\title{
EDUCAÇÃO SUPERIOR NO BRASIL CONTEMPORÂNEO: TRANSIÇÃO PARA UM SISTEMA DE MASSA*
}

\author{
Alfredo Macedo Gomes ${ }^{* *}$ \\ KARINE NUMES DE MORAES ${ }^{* * * *}$
}

\begin{abstract}
RESUMO: O estudo analisa o processo de expansão da educação superior no Brasil nas últimas três décadas, com especial atenção para o período que cobre os governos Fernando Henrique Cardoso e Luis Inácio Lula da Silva. Examinam-se as seguintes questões: podemos afirmar que o Brasil contemporâneo produziu um sistema de massa? Se sim, como e por meio de que políticas têm se processado a mudança para o sistema de educação superior de massa? Para analisar tal problemática nos apoiamos principalmente na perspectiva teórica desenvolvida por Trow e nos dados estatísticos gerados pelo Censo da Educação Superior e pelo Instituto Brasileiro de Geografia e Estatística. A principal linha de argumentação gira em torno da transformação da educação superior em "sistema de massa", indicando fases de crescimento, características predominantes e por meio de quais políticas tem se processado a transição do sistema de elite para o sistema de educação superior de massa.
\end{abstract}

Palavras-chave: Educação superior. Sistema de elite. Sistema de massa. Brasil.

\section{Higher EDUCATION IN CONTEMPORARY BRAZIL: TRANSITION TO A MASS' SYSTEM}

\begin{abstract}
The study examines the expansion of higher education in Brazil in the last three decades, with special attention to the period covering the governments of Fernando Henrique Cardoso and Luiz Inácio Lula da Silva. It addresses the following questions: Can you say that Brazil has produced a mass' higher education system? If so, how and whereby policies and initiatives have taken place the changes? To analyse this problem we mainly rely on the theoretical perspective developed by Martin Trow, and the statistics generated by the Census of Higher Education and the Brazilian Institute
\end{abstract}

Pesquisa realizada com fomento de CNPq, Facepe e Capes.

* Pós-doutor em Educação e professor do Departamento de Fundamentos Sociofilosóficos da Educação e do Programa de Pós-Graduação em Educação da Universidade Federal de Pernambuco (UFPE). E-mail: alfredomgomes@gmail.com

*** Doutoranda do Programa de Pós-Graduação em Educação da Universidade Federal de Pernambuco (UFPE) e professora da Universidade Federal de Goiás (UFG). E-mail: karine.ufg@gmail.com 
of Geography and Statistics. The main line of argument turns on the transformation of higher education into a "mass system", indicating phases of growth, predominant features and policies through which have been processed the transition from system elite to mass' higher education system.

Key words: Higher education. Elite's system. Mass' system. Brazil.

\section{ENSEIGNEMENT SUPÉRIEUR DANS LE BRÉSIL CONTEMPORAIN:}

\section{LA TRANSITION VERS UN SYSTÈME DE MASSE}

RÉSUMÉ: L'étude analyse le processus d'expansion de l'éducation supérieure au Brésil dans les trois dernières décennies, en particulier pendant les gouvernements Cardoso et Lula. On y discute les questions suivantes: peut-on affirmer que le Brésil contemporain a créé un système éducatif de masse? Si oui, comment et au moyen de quelles politiques s'est fait le changement vers un système d'éducation supérieure de masse? Pour essayer d'analyser un tel problème on s'appuie sur les théories développées par Trow et sur les données statistiques du Recensement de l'Éducation Supérieure et sur les données de l'Institut Brésilien de Géographie et Statistique. Notre principale ligne d'argumentation tient à la transformation de l'éducation supérieure en «système de masse», en passant par des périodes de croissance, des caratéristiques dominantes et par des politiques de transition d'un système d'élite vers un système d'éducation supérieure de masse.

Mots-clés: L'enseignement supérieur. Système d'élite. Système de masse. Brésil.

\section{Introdução}

A

s grandes transformações do campo da educação podem ser observadas como acontecimentos históricos que indicam fases caracterizáveis e passíveis de delimitação e construção empírico-analítica. É o caso a ser observado em relação ao processo de expansão da educação superior no Brasil quando tomado em seu curso histórico a partir de 1810? Pode-se afirmar que a educação superior (ES) brasileira se encontra massificada? Que critérios e evidências poderão levar a tal conclusão? Para analisar a problemática da expansão da ES no Brasil, iremos nos apoiar no trabalho de Trow $(1973,2005)$ e nos dados estatísticos gerados pelo Censo da Educação Superior e pelo Instituto Brasileiro de Geografia e Estatística.

Trow defende a tese de que a transição histórica dos sistemas de ES tende a seguir três fases nas sociedades avançadas: "sistema de elite" para o "sistema de massa" e deste para o "sistema de acesso universal". A partir desta perspectiva teórica apresentada, em linhas gerais, a seguir, iremos então analisar os dados que reunimos sobre a ES no Brasil e apresentar uma determinada linha de argumentação em torno da sua transformação em "sistema de massa", visando contribuir com o debate acadêmico sobre as políticas de expansão contemporaneamente.

A compreensão aprofundada de cada uma dessas fases implica um duplo movimento por parte do pesquisador: por um lado, procurar entender a ES, em 
quaisquer de suas fases, na especificidade e nas dimensões em que se apresenta social e historicamente, e, por outro lado, procurar articular por que a sociedade produziu, a partir das políticas públicas coordenadas pelo Estado, o estágio atual da ES com as características que o matizam. Ao estudar estas duas dimensões do problema, que são, na verdade, uma só, divisível apenas na aparência da exposição e do método, pode-se contribuir para entendê-lo tanto em perspectiva sincrônica quanto diacrônica.

\section{Expansão da educação superior: fases, dimensões e características}

Trow (2005) elabora um conjunto de dimensões para pensar a transição do "sistema de elite" para o "sistema de massa" e deste para "sistema de acesso universal". As dimensões são as seguintes: tamanho do sistema, funções, currículo e formas de instrução, "carreira" do estudante, diversificação institucional, locus de poder e de decisão, padrões acadêmicos, políticas de acesso e seleção, formas de administração acadêmica e governança interna. ${ }^{1}$ Não exploramos aqui todas as dimensões em relação ao caso brasileiro. Na verdade, o objetivo é bem mais modesto. Visa discutir as seguintes questões: podemos afirmar que o Brasil contemporâneo produziu um sistema de massa? Se sim, quais são suas características predominantes? Como e por meio de que políticas e iniciativas tem se processado a mudança para o sistema de ES de massa?

Em relação às dimensões formuladas por Trow (2005), destaca-se que o autor não toma apenas a dimensão quantitativa (tamanho e volume do sistema) para pensar a ES. Esta é uma dimensão fundante da sua perspectiva analítica, mas as demais dimensões ocupam espaço importante, tanto do ponto de vista epistemológico quanto metodológico. Esta observação é pertinente porque a perspectiva analítica em foco não é uma teoria pura da expansão da ES. É mais compreensiva, como se pode deduzir das dimensões mencionadas. Trow (1973) destaca que a problemática que a ES enfrenta nas sociedades avançadas pode ser mais bem compreendida como diferentes manifestações de um conjunto de problemas relacionados, os quais emergem da transição de uma fase para outra em um padrão amplo do desenvolvimento da ES, a transição - em andamento em toda sociedade avançada - do sistema de elite para o de massa e, subsequentemente, para o sistema de acesso universal. Subjacente a esse padrão de desenvolvimento estão o ritmo e o volume do crescimento, os quais, juntos, fazem emergir problemas de várias ordens nas mais diferentes partes do sistema: nas formas de acesso e seleção, na qualidade do ensino, na distribuição do currículo, na organização e realização da pesquisa, na gestão das universidades e demais instituições não universitárias.

Dentre as manifestações do crescimento do Sistema de Educação Superior (SES) são destacadas três que se relacionam mutuamente e desencadeiam diferentes 
tipos de problemas, provocando transformações importantes nesse sistema: 1) a taxa de crescimento da matrícula (TCM); 2) o tamanho absoluto do sistema e das instituições individualmente; e 3) a proporção do grupo etário de 18 a 24 anos matriculado (Trow, 2005). No caso da TCM, que evidencia o ritmo da expansão, produz uma grande tensão sobre as estruturas de governança, de administração e da socialização de alunos e professores. Como consequencia, leva ao enfraquecimento das formas mais tradicionais de relações da comunidade acadêmica. $\mathrm{O}$ ingresso crescente de parcelas da população faz incorporar de forma igualmente crescente diferenças sociais, econômicas, culturais, étnico-raciais e regionais às IES, e tende a colocar em xeque o mandato e o modus operandi deste nível de ensino. A presença mais significativa de estudantes oriundos das classes trabalhadoras e das denominadas minorias recoloca na mesa, sob novas perspectivas, as discussões sobre as políticas de igualdade e equidade sociais e educativas antes vistas como questão secundária, pressionando governos no sentido da formulação de políticas compensatórias e afirmativas. Além disso, o aumento de proporções significativas de determinado grupo etário tende a interferir na organização e no clima institucional, bem como na estrutura curricular, promovendo um processo paulatino de diferenciação e diversificação institucional (Trow, 2005).

A causa irradiadora do processo de transição de uma fase para outra do sistema reside no volume de matrícula. Para Trow (op. cit.), o sistema de elite tende a atender até $15 \%$ do grupo etário de 18 a 24 anos, sendo que o acesso se dá quase que exclusivamente em função da origem de classe social dos estudantes, tem uma relação direta com o nascimento e a renda e constitui privilégio social associado aos mecanismos meritocráticos da escolarização básica e fruto da seleção social (Bourdieu, 2001). Sendo o acesso controlado e regulado de dentro, a expansão do sistema de elite também se dá de modo que se garanta a manutenção de uma rígida tradição acadêmica, expressa na estrutura e oferta de seus cursos, baseada numa relação professor/estudante mais pessoal e orientada. O sistema de elite é organizado a fim de não alterar sua característica fundamental, qual seja, formar a classe social dominante para as funções de elite, estruturando-se como elemento de "proteção" e "distinção" de classe social.

Segundo Trow, o sistema de massa é definido por atender entre $16 \%$ e $50 \%$ do grupo etário de 18 a 24 anos, estando plenamente consolidado em relação ao sistema de elite quando passa a admitir mais de 30\% das matrículas do grupo etário relevante. $\mathrm{O}$ volume de matrícula é uma variável central no processo de transição de um sistema para o outro, ao qual se articulam outras características que o sistema passa a apresentar. Em primeiro lugar, a população estudantil não é apenas composta pelos estudantes oriundos da elite social, econômica e cultural. A ES deixa de ser vista como privilégio de nascimento e classe social, e passa a ser concebida 
como "um direito para aqueles com certas qualificações" (Trow, 2005, p. 5). Assim, o sistema de massa tende a responder a demandas e interesses de um público bem mais amplo e diferenciado proveniente das classes sociais cujos filhos/as concluíram o ensino médio. Mesmo mantendo-se uma perspectiva meritocrática, as formas de acesso e seleção ao sistema de massa se processam pela incorporação de critérios políticos, isto é, exames de ingresso e critérios estabelecidos por políticas compensatórias, as quais visam garantir igualdade de oportunidades, claro, dentro dos limites da democracia liberal. O ingresso de um contingente maior de estudantes fortalece os movimentos para alterar os mecanismos de acesso e seleção, em face da superação da concepção de ES como privilégio (de classe), que cede lugar à ancoragem social da educação como direito. Ampliado e diversificado, o sistema de massa tende a ser transformado em sua estrutura de ensino, na ampliação numérica da relação professor/estudante e na estrutura burocrático-administrativa de suas IES. Obviamente que tal processo não se faz naturalmente, mas em função de políticas públicas. Como o sistema de massa passa a ter uma vinculação mais estreita e sistemática com as estruturas produtiva e de emprego da sociedade capitalista contemporânea, a ES tende a converter-se em ensino, na forma de transmissão de conhecimentos gerais e específicos, técnicos e profissionais, formando quadros para os diversos setores da economia e da sociedade. Trow (2005) aponta que o impacto da transição para o sistema de massa é sentida: na organização curricular, que se apresenta mais flexível e modular, por meio de créditos, com ênfase cada vez maior no desenvolvimento de competências; na preparação para o mercado de trabalho e o desenvolvimento de carreiras profissionais; na diferenciação e diversificação das IES; na implementação de políticas compensatórias; na maior especialização, racionalização e complexidade do trabalho administrativo e gerencial nas IES, tendo a avaliação o papel de "medir" a eficiência das instituições; e no desenvolvimento de formas mais democráticas de participação.

O sistema de acesso universal caracteriza-se por um volume de matrículas que compreende mais de 50\% da coorte de 18 a 24 anos. Nesse caso, segundo Trow (op. cit., p. 18), o acesso passa a ser definido como "uma obrigação para as classes média e média alta", além de ser uma forma de justiça social, uma vez que se apresenta muito mais como uma questão de conquista da igualdade entre grupos e classes do que de igualdade de oportunidades individuais. O acesso é aberto no sentido de que a conclusão do ensino secundário é o requisito fundamental, porém a seleção e o ingresso aos cursos tornam-se um problema para a capacidade de provimento das IES, que passam a ser disputadas pelos estudantes na medida da reputação de seus cursos, e, no caso brasileiro, também em função da gratuidade do setor público. Como o sistema de acesso universal não objetiva a formação exclusiva das elites, muito embora o sistema comporte IES de elite (altamente seletivas com cursos altamente 
competitivos), a maior preocupação do sistema de acesso universal é a adaptação de toda a população à sociedade marcada por rápido processo de transformação econômica, social e tecnológica (Brennan, 2004; Scott, 1995).

A partir do trabalho de Trow, cujas linhas centrais foram brevemente expostas, podemos então analisar determinados aspectos da ES no Brasil. O critério de análise amplamente utilizado na literatura da área, como exposto acima, leva em consideração a matrícula líquida (18 a 24 anos). Esclarecemos, porém, que iremos analisar o caso brasileiro tomando como referência, a partir da Tabela 1, a matrícula líquida (ML) e, a partir da Tabela 2, a matrícula bruta (ML), que corresponde a toda a população matriculada independentemente de idade.

\section{Do sistema de elite ao sistema de massa: o caso da ES no Brasil}

A análise compreende um período importante da história contemporânea brasileira, a qual, por razões óbvias, não é possível detalhar aqui. Todavia, é importante explicitar, brevemente, que o período entre 1980 e 1985 é parte de uma fase em que se operou a "abertura" (Weffort, 1984) gradual e lenta, que se prolonga, entre 1985 e 1989, como "transição conservadora" (Saviani, 2007) da Nova República, culminando, em 1989, na primeira eleição presidencial depois do golpe de 1964, pavimentando, dentro do contexto social e político então vigente, o processo da redemocratização no Brasil. O período de 1990 a 1994 constitui, em face dos acontecimentos políticos, um período importante da experiência democrática recente, embora marcado por grande indefinição do ponto de vista das políticas públicas. A partir de 1995, sucedem-se períodos de governos eleitos pelo sistema de democracia representativa: o governo de Fernando Henrique Cardoso (Governo FHC, 19952002), formado por uma aliança liberal-conservadora, com políticas claramente de corte privatista para a ES (Oliveira \& Catani, 2002; Oliveira, Catani \& Dourado, 2001; Cunha, 2000, 2003; Dourado, 2002; Gomes, 2003, 2008; Chauí, 2000; Sguissardi, 2008; Sguissardi \& Silva Jr. 2001), sendo sucedido pelo governo de Luis Inácio Lula da Silva (Governo Lula, 2003-2010), formado por uma aliança liberal-popular, também com políticas claramente definidas para a ES (Dourado, 2009; Paula, 2009; Gomes, 2008; Sguissardi, 2008). Os resultados de tais políticas, independentemente das especificidades e dos fundamentos político-discursivos, irão repercutir consistentemente na expansão da ES, como os dados analisados a seguir demonstram.

A Tabela 1 contém dados anuais de 1991 a 2008 sobre a população de 18 a 24 anos, matrícula líquida (ML) e razão população de 18 a 24 anos/ML, assim como as TCM e médias anuais calculadas para três períodos: o período corresponde a 1995 até 2008 e aos governos FHC e Lula. 


\section{Tabela 1}

População de 18 a 24 anos e matrícula líquida na educação superior - Brasil: 1991 a 2008

\begin{tabular}{|c|c|c|c|}
\hline Ano & $\begin{array}{c}\text { População } \\
18 \text { a } 24 \text { anos }\end{array}$ & $\begin{array}{c}\text { ML } \\
\left(_{(18 \text { a } 24 \text { anos })^{(1)}}\right.\end{array}$ & Pop. 18-24 anos/ML (\%) \\
\hline 1991 & 19.352 .693 & 833.186 & 4,3 \\
\hline 1995 & 18.737 .006 & 1.104 .783 & 5,9 \\
\hline 1996 & 19.491 .000 & 1.131 .482 & 5,8 \\
\hline 1997 & 19.634.957 & 1.238 .121 & 6,3 \\
\hline 1998 & 20.350 .699 & $1.389 .111^{(2)}$ & 6,8 \\
\hline 1999 & 20.977 .857 & 1.567 .917 & 7,4 \\
\hline 2000 & 23.365.185 & 1.722 .446 & 7,4 \\
\hline 2001 & 22.940 .218 & 2.070 .441 & 9,0 \\
\hline 2002 & 23.098 .462 & 2.316 .184 & 9,9 \\
\hline Taxa de crescimento 95/02 & $23,3 \%$ & $178 \%$ & \\
\hline Média anual & $2,9 \%$ & 22,2 & \\
\hline 2003 & 23.371.702 & 2.548 .402 & 10,8 \\
\hline 2004 & 24.072 .318 & 2.557 .735 & 10,6 \\
\hline 2005 & 24.405 .518 & 2.769 .418 & 11,3 \\
\hline 2006 & 24.285 .000 & 3.091 .000 & 12,7 \\
\hline 2007 & 23.845 .000 & 3.151 .000 & 13,2 \\
\hline 2008 & 23.242 .000 & 3.221 .000 & 13,9 \\
\hline Taxa de crescimento $02 / 08$ & $-0,5 \%$ & $26,4 \%$ & \\
\hline Média anual & $-0,08 \%$ & $4,4 \%$ & \\
\hline Taxa de crescimento 95/08 & $24 \%$ & $191,5 \%$ & \\
\hline Média anual & $1,7 \%$ & $13,7 \%$ & \\
\hline
\end{tabular}

Fonte: IBGE: Censos 1991 e 2000; PNAD, respectivos anos. Notas: 1) Inclui estudantes de cursos de mestrado e doutorado; 2) Estimativa realizada pelos autores. Tabela construída pelos autores.

Em 1991, a razão entre população e matrícula do grupo etário de 18 a 24 anos foi de 4,3\%; em 2002, final do Governo FHC, passa para 9,9\% e alcança, em 2008, $13,9 \%$. A TCM líquida (178\%) é praticamente duas vezes o da bruta (97,7\%, ver Tabela 2) durante o Governo FHC, com média anual de 22,2\%. A expansão da ML continua no Governo Lula, porém com média anual $(4,4 \%)$ bem inferior, mas igualmente 
forte. Todavia, no período analisado referente ao Governo Lula, o crescimento da ML (26,4\%) é inferior ao crescimento da bruta (30,7\%). Além disso, a expansão da matrícula coincide com o crescimento negativo da população de 18 a 24 anos.

O ritmo de forte crescimento da ML é claramente evidente a partir de meados da década de 1990. Durante o período que cobre os dois governos, a TCM líquida foi de 191,5\%, uma média anual da ordem de 13,7\%. Essa taxa é apenas ligeiramente superior à TCM bruta do período (ver Tabela 3). Tomando como referência a razão entre população de 18 a 24 anos/ML, o sistema brasileiro de educação superior pode ainda ser caracterizado como "sistema de elite". Todavia, tendo em vista o peculiar desenvolvimento da educação brasileira, mais de $30 \%$ da população que ingressa na ES o faz em grande distorção série/idade, aprofundaremos a análise a partir dos dados da matrícula bruta.

A Tabela 2 reúne dados relativos ao período histórico, população de 18 a 24 anos, matrícula bruta (MB) e razão entre população de 18 a 24 anos/MB. Organizamos os dados com o fim de colocar em destaque quatro períodos. As taxas e médias anuais de crescimento foram calculadas para três períodos, a fim de possibilitar a perspectiva comparativa e o embasamento das considerações.

\section{Tabela 2}

População de 18 a 24 anos e matrícula bruta na educação superior - Brasil: 1980-2008

\begin{tabular}{|l|c|c|c|}
\hline Ano & $\begin{array}{c}\text { População } \\
\mathbf{1 8} \text { a 24 anos }\end{array}$ & MB $^{(\mathbf{1})}$ & Pop. 18-24 anos/MB (\%) \\
\hline 1980 & $16.000 .000^{(2)}$ & 1.377 .286 & 8,6 \\
\hline 1981 & 16.104 .335 & 1.386 .792 & 8,6 \\
\hline 1982 & 16.552 .034 & 1.407 .987 & 8,5 \\
\hline 1983 & 16.834 .011 & 1.438 .992 & 8,5 \\
\hline 1984 & 17.575 .446 & 1.399 .539 & 8,0 \\
\hline 1985 & 17.821 .209 & 1.367 .609 & 7,7 \\
\hline 1986 & 18.240 .176 & 1.418 .196 & 7,8 \\
\hline 1987 & 18.449 .578 & 1.470 .555 & 8,0 \\
\hline 1988 & 18.545 .653 & 1.503 .555 & 8,1 \\
\hline 1989 & 18.557 .266 & 1.518 .904 & 8,2 \\
\hline 1990 & 18.680 .776 & 1.540 .080 & 8,2 \\
\hline 1991 & 19.352 .693 & 1.565 .056 & 8,0 \\
\hline 1992 & $18.956 .519^{(2)}$ & 1.535 .788 & 8,1 \\
\hline
\end{tabular}




\begin{tabular}{|c|c|c|c|}
\hline 1993 & 18.560 .344 & 1.594 .668 & 8,5 \\
\hline 1994 & $18.648 .675^{(3)}$ & 1.661 .034 & 8,9 \\
\hline Taxa de crescimento 80/94 & $16,5 \%$ & $20,6 \%$ & \\
\hline Média anual & $1,1 \%$ & $1,4 \%$ & \\
\hline 1995 & 18.737 .006 & 1.759 .703 & 9,3 \\
\hline 1996 & 19.491 .000 & 1.868 .529 & 9,6 \\
\hline 1997 & 19.634 .957 & 1.945 .615 & 9,9 \\
\hline 1998 & 20.350 .699 & 2.125 .958 & 10,4 \\
\hline 1999 & 20.977 .857 & 2.369 .945 & 11,3 \\
\hline 2000 & 23.365 .185 & 2.694 .245 & 11,5 \\
\hline 2001 & 22.940 .218 & 3.030 .754 & 13,2 \\
\hline 2002 & 23.098 .462 & 3.479 .913 & 15,1 \\
\hline Taxa de crescimento 95/02 & $23,3 \%$ & $97,7 \%$ & \\
\hline Média anual & $2,9 \%$ & $12,2 \%$ & \\
\hline 2003 & 23.371 .702 & 3.887 .022 & 16,6 \\
\hline 2004 & 24.072.318 & 4.163 .733 & 17,3 \\
\hline 2005 & 24.405 .518 & 4.453 .156 & 18,2 \\
\hline 2006 & 24.285.000 & 4.676 .646 & 19,2 \\
\hline 2007 & 23.845 .000 & 4.880 .381 & 20,3 \\
\hline 2008 & 23.242 .000 & 5.080 .056 & 21,8 \\
\hline Taxa de crescimento 95/02 & $0,5 \%$ & $30,7 \%$ & \\
\hline Média anual & $-0,08 \%$ & $5,1 \%$ & \\
\hline Taxa de crescimento 95/02 & $24 \% \%$ & $188,7 \%$ & \\
\hline Média anual & $1,7 \%$ & $13,5 \%$ & \\
\hline
\end{tabular}

Fontes: IBGE; MEC/Inep. Notas: 1) Toda população estudantil matriculada nos cursos de graduação presencial independentemente da idade; 2) Estimativa realizada pelos autores; 3) Estimativa realizada pelos autores a partir da média do ano anterior e posterior. Tabela construída pelos autores.

Durante o período de 1980 a 1994, que testemunhou decisivos momentos do processo de redemocratização no Brasil, a TCM bruta, de 16,5\% (média anual de $1,1 \%$ ), foi significativamente baixa, o que reflete a ausência de políticas públicas para ampliar o acesso da população estudantil à ES. A partir de 1995, início do Governo FHC, a ES passa a apresentar taxas crescentes de expansão, tendo continuidade no Governo Lula. Gostaríamos de chamar a atenção para o ciclo ascendente de expansão da ES que caracteriza o período que compreende os dois governos, sob políticas públicas que expressam evidentes continuidades e importantes diferenças (Gomes, 2008). 
Considerando-se a relação entre população de 18 a 24 anos e $\mathrm{MB}$, o sistema de ES pode ser caracterizado como "sistema de elite" até por volta de 2002, porque, durante o período compreendido entre 1980 e 2002, a população matriculada passou de $8,6 \%$ para pouco mais de $15 \%$. É somente em 2003 que o volume de matrículas atinge a casa dos $16 \%$. É, portanto, segundo a terminologia de Trow, a partir desse período que se ultrapassa a linha divisória imaginária que marca a transição do "sistema de elite" para o "sistema de massa", quando o volume de matrícula alcança, em número absoluto, em 2003, o total de 3.887.022, o que representa quase três vezes o número de matrículas registradas em 1980. Todavia, o leitor deve estar atento para a inconveniência de esta primeira conclusão ser baseada na $\mathrm{MB}$, que inclui estudantes abaixo e acima da faixa etária de 18 a 24 anos. Apesar disso, nós vamos defender a tese da construção política de um sistema de massa no Brasil.

Além de esta primeira conclusão indicar o processo de transição do sistema de elite para o sistema de educação superior de massa, é importante chamar a atenção - conforme os dados demonstram - para o fato de que tal processo se inicia ali por volta de 1995, segundo ano do programa de estabilização da moeda, a partir do Plano Real (1994), e primeiro ano de um ciclo de políticas consistentes e claramente voltadas para a expansão da ES (Brasil, 2000a; 2000c). Foi em 1995 que a TCM bruta ultrapassou o patamar de 9,0\% em relação à população de 18 a 24 anos, depois de 15 anos praticamente estacionada na casa dos $8 \%$.

A TCM bruta, para 1995-2002, é da ordem de 97,7\%, com expressiva média anual de crescimento de $12,2 \%$, o que reflete as políticas neoliberais implementadas pelo Governo FHC: a clara opção de fortalecimento do setor privado (Sguissardi \& Silva Jr., 2001; Corbucci, 2004; Pinto, 2004) mediante a criação de um moderno mercado de ES no Brasil (Gomes, 2002; Cunha, 2004). Observa-se também que a TCM bruta, no período, é muito superior à taxa de crescimento da população de 18 a 24 anos, o que implica expansão real.

O Governo Lula dá continuidade ao processo de expansão, por meio de novas iniciativas, o que é verificado pelo aumento da razão entre população de 18 a 24 anos/MB, que passa de aproximadamente 16\% em 2003 para 21,8\% em 2008. A TCM bruta no período é de 30,7\%, uma média anual de 5,1\%. Os dados demonstram que, pela primeira vez, a taxa de crescimento da população de 18 a 24 anos é negativa, o que contribuiu para a expansão real do sistema, ao lado da implementação de políticas sistemáticas voltadas para a incorporação da população estudantil na ES.

Considerando o período de 1995 a 2008, uma segunda conclusão pode ser apontada: a expansão das matrículas e o crescimento do sistema são resultados de políticas públicas sistemáticas, levadas a efeito por um longo período. Neste caso específico, há correlação positiva com a diminuição do ritmo de crescimento da população 
da faixa etária relevante e também com a melhora relativa da economia nacional a partir da criação do real.

Podemos afirmar que, durante o Governo FHC, o Brasil adota políticas de intensificação da matrícula, sobretudo via setor privado, dando início ao processo de transição para o sistema de massa, processo que tem continuidade no Governo Lula, em face de todo um conjunto de políticas que apontam para a construção do sistema de massa. Diante do exposto, chegamos então a uma terceira conclusão, qual seja: a criação de um sistema de massa no Brasil tem sido perseguida contemporaneamente, antes de tudo como política de Estado, ${ }^{2}$ evidenciada, apesar das hesitações e contradições que a caracterizam, na meta de "prover, até o final da década, a oferta de educação superior para, pelo menos, 30\% da faixa etária de 18 a 24 anos" (Brasil, 2001). Estamos muito distantes de realizar essa meta, pois ela se refere à matrícula líquida. O sistema de massa em construção reflete as distorções típicas da escolarização básica, o que representa uma proporção considerável de estudantes acima de 24 anos.

A Tabela 3 possibilita a visualização do processo de expansão a partir da comparação entre o crescimento das ML e MB. Na segunda coluna encontram-se os dados da MB, seguidos da ML e, na quarta coluna, a relação entre ML/MB. A quinta coluna contém a diferença entre MB e ML. Os dados nos levam a duas considerações importantes: 1) o crescimento da ML foi mais significativo entre 1995 e 2003, sofrendo uma ligeira queda a partir de 2003, mas mantendo-se na casa dos 60\%; 2) há tendência de crescimento real da ML nos próximos anos, particularmente porque a taxa média de conclusão do ensino médio tende a crescer ao mesmo tempo que o crescimento da população da faixa etária de 18 a 24 anos tende a ser negativo ou crescer abaixo da expansão da ML.

Tabela 3

Matrículas bruta e líquida educação superior - Brasil: 1991-2008

\begin{tabular}{|c|c|c|c|c|}
\hline Ano & $\mathbf{M B}^{(1)}$ & $\mathbf{M L}^{(2)}$ & \% ML/MB & MB-ML \\
\hline 1991 & 1.565 .056 & 833.186 & $53,2 \%$ & 731.870 \\
\hline 1995 & 1.759 .703 & 1.104 .783 & $62,8 \%$ & 654.920 \\
\hline 1996 & 1.868 .529 & 1.131 .482 & $60,6 \%$ & 737.047 \\
\hline 1997 & 1.945 .615 & 1.238 .121 & $63,6 \%$ & 707.494 \\
\hline 1998 & 2.125 .958 & $1.389 .111^{(\mathrm{a})}$ & 65,3 & 736.847 \\
\hline 1999 & 2.369 .945 & 1.567 .917 & 66,2 & 802.028 \\
\hline 2000 & 2.694 .245 & 1.722 .446 & 63,9 & 971.799 \\
\hline
\end{tabular}




\begin{tabular}{|l|l|l|l|l|}
\hline 2001 & 3.030 .754 & 2.070 .441 & 68,3 & 960.313 \\
\hline 2002 & 3.479 .913 & 2.316 .184 & 66,6 & 1.163 .729 \\
\hline 2003 & 3.887 .022 & 2.548 .402 & 65,6 & 1.338 .620 \\
\hline 2004 & 4.163 .733 & 2.557 .735 & 61,4 & 1.605 .998 \\
\hline 2005 & 4.453 .156 & 2.769 .418 & 62,2 & 1.683 .738 \\
\hline 2006 & 4.676 .646 & 3.091 .000 & 66,1 & 1.585 .646 \\
\hline 2007 & 4.880 .381 & 3.151 .000 & 64,6 & 1.729 .381 \\
\hline 2008 & 5.080 .056 & 3.221 .000 & 63,4 & 1.859 .056 \\
\hline
\end{tabular}

Fontes: MEC/Inep. Notas: 1) Toda população estudantil matriculada nos cursos de graduação presencial independentemente da idade; 2) Inclui estudantes de cursos de mestrado e doutorado; a) Estimativa realizada pelos autores. Tabela construída pelos autores.

A análise realizada até aqui não nos permite entender como e por meio de quais políticas e medidas tem se processado a transição para o sistema de massa. De forma muito abreviada, trataremos desta questão a seguir. Tendo em vista o período estudado, uma primeira medida neste processo foi a imposição da Gratificação de Estímulo à Docência ao Magistério Superior (Brasil, 1998), que teve implicações diretas no processo de reorganização da atividade docente das Ifes. O impacto da implementação da GED teve alguma repercussão no aumento da matrícula das Ifes, que aumentou de 367.531 em 1995 para 531.634 em 2002. Todavia, não está muito claro se a GED propiciou o aumento da razão professor-aluno, como era seu objetivo (Brasil, 2000b). A GED também contribuiu para a ampliação dos cursos noturnos, ao mesmo tempo em que foi acompanhada da queda dos recursos financeiros para as Ifes (Amaral, 2003).

Outro programa que teve impacto para o processo de expansão foi o Fundo de Financiamento ao Estudante do Ensino Superior (Brasil, 1999), o qual se destina a financiar a graduação de estudantes regularmente matriculados nas IES privadas. Até 2007 mais de 500 mil estudantes contraíram empréstimos para financiar seus estudos e isso repercutiu no crescimento das matrículas no setor privado/mercantil (Sguissardi, 2008). Há estudos que analisam, com maior ou menor aprofundamento, aspectos das políticas de expansão coordenadas pelo Governo FHC (Cunha, 2003; Sguissardi, 2008; Dourado, 2002; Oliveira, 2000; Dias Sobrinho, 2002; Gomes, 2003; Pinto, 2004; Amaral, 2003), mas gostaríamos de resumir explicitando que

(...) a expansão da educação superior foi realizada mediante financiamento privado, doméstico, com a participação ativa do "consumidor de serviços educacionais", numa clara definição da educação superior como mercadoria, o que cristaliza a marca da política liberal-conservadora deste governo, com a tentativa de apagamento, na memória discursiva da população, da ideia de educação como direito. Para o sucesso desse 
processo, teve papel fundamental a implementação de mecanismos de avaliação que estabeleceram a competitividade como motor de dinamização do moderno mercado da educação superior por meio da ampla divulgação que o governo e a mídia davam aos resultados do Exame Nacional de Cursos, o Provão. (Gomes, 2008, p. 28-29)

A Tabela 4 contém a expansão da ES em relação aos setores público e privado concernente aos governos FHC e Lula. Os dados da expansão da matrícula no setor privado corroboram a leitura explicitada acima, em dois sentidos: 1) durante o Governo FHC, a matrícula do setor privado teve uma TCM de 129,3\%, muito superior ao crescimento da matrícula do setor público $(50,1 \%)$. O setor privado amplia sua participação no cômputo geral de matrícula de $60,2 \%$ para $69,8 \%$, ao passo que o setor público encolhe de $39,8 \%$ para $30,2 \%$; 2) em linha de continuidade, o setor privado $(38,4 \%)$ mantém um ritmo de crescimento superior ao do setor público $(12,1 \%)$ durante o Governo Lula, que alcança $74,9 \%$, e diminuição relativa da participação do setor público para 25,1\%.

A TCM do setor privado foi, no período de 1995 a 2008, de 259,3\% (média anual de $18,5 \%$ ), ao passo que o setor público cresceu $81,8 \%$ (média anual de $5,8 \%$ ). Tais dados são suficientemente robustos para sustentar a tese de continuidade na política de expansão durante os governos FHC e Lula ou, como colocamos anteriormente, trata-se de uma política de Estado.

\section{Tabela 4}

Matrícula bruta na educação superior por setor - Brasil: 1995-2008

\begin{tabular}{|l|c|c|c|}
\hline Ano & Público & Privado & Total \\
\hline \multirow{2}{*}{1995} & $\begin{array}{c}700.540 \\
39,8 \%\end{array}$ & $\begin{array}{c}1.059 .163 \\
60,2 \%\end{array}$ & 1.759 .703 \\
\hline \multirow{2}{*}{2002} & 1.051 .655 & 2.428 .258 & 3.479 .913 \\
\hline Taxa de crescimento 95/02 & $30,2 \%$ & $69,8 \%$ & $97,7 \%$ \\
Média anual & $50,1 \%$ & $129,3 \%$ & $12,2 \%$ \\
\hline \multirow{2}{*}{2008} & $6,3 \%$ & $16,1 \%$ & 5.080 .056 \\
\hline Taxa de crescimento 02/08 & 1.273 .965 & 3.806 .091 & $30,7 \%$ \\
Média anual & $25,1 \%$ & $74,9 \%$ & $5,1 \%$ \\
\hline Taxa de crescimento 95/08 & $12,1 \%$ & $38,4 \%$ & $188,7 \%$ \\
Média anual & $2,0 \%$ & $6,4 \%$ & $13,5 \%$ \\
\hline
\end{tabular}

Fonte: MEC/Inep. Toda população estudantil matriculada nos cursos de graduação presencial independentemente da idade. 
O ritmo acelerado de expansão teve continuidade a partir de 2003, mas sob nova tônica. Articulado ao discurso de democratização da ES (como "bem público" ou de "interesse público"), uma série de políticas vem sendo implementada ou reorientada, objetivando ampliar o acesso, sobretudo dos jovens e trabalhadores provenientes das classes sociais tradicionalmente excluídas da ES. O Governo Lula implanta programas que têm impacto direto na expansão do setor privado. O Programa Universidade para Todos (Prouni), criado pela Medida Provisória n 213/2004 e institucionalizado pela Lei n. 11.096/2005, caracteriza-se pela oferta de bolsas de estudo integrais e parciais a estudantes oriundos da escola pública e pertencentes às classes sociais de baixa renda em IES privadas (Oliveira, 2007). A tabela 5 mostra a evolução da oferta de bolsas integrais e parciais no período de 2005 a 2009, cujo volume total se aproxima de 900 mil bolsas. O Prouni representa uma forma diferente de promoção da expansão, em primeiro lugar por definir como público-alvo a população de baixa renda e de escola pública e, em segundo lugar, porque o seu financiamento é por meio de recursos públicos (Gomes, 2008).

\section{Tabela 5}

Número de bolsas ofertadas pelo Prouni - Brasil: 2005-2009

\begin{tabular}{|l|c|c|c|}
\hline Ano & Integral & Parcial & Total \\
\hline 2009 & 153.126 & 94.517 & 247.643 \\
\hline 2008 & 99.495 & 125.510 & 225.005 \\
\hline 2007 & 95.631 & 66.223 & 163.854 \\
\hline 2006 & 98.698 & 39.970 & 138.668 \\
\hline 2005 & 91.609 & 28.073 & 119.682 \\
\hline Total & $\mathbf{5 3 8 . 5 5 9}$ & $\mathbf{3 5 4 . 2 9 3}$ & $\mathbf{8 9 4 . 8 5 2}$ \\
\hline
\end{tabular}

Fonte: Sisprouni.

No que se refere às Ifes, a política de expansão no Governo Lula destaca-se pelas seguintes medidas: o Programa Expansão das Ifes tem como meta a implantação de 10 novas universidades federais e a criação ou consolidação de 49 campi nas cinco regiões brasileiras, com vistas a promover a inclusão social, reduzir as desigualdades regionais e "reorientar a organização do ensino superior no Brasil" (Brasil, 2006, p. 11). O impacto esperado é de 30 mil novos estudantes em cursos de graduação em 2008. ${ }^{3}$ A integração de Instituições Federais de Educação Profissional e Tecnológica (Decreto $n^{\circ}$ 6.095, de 24 de abril de 2007) objetiva a constituição de Instituições Federais de Educação, Ciência e Tecnologia (Ifet), mediante a celebração para formalizar a agregação "voluntária" dos Centros Federais de 
Educação Tecnológica, Escolas Técnicas Federais, Escolas Agrotécnicas Federais e Escolas Técnicas vinculadas às universidades federais, localizados em um mesmo estado (Brasil, 2007a). Neste sentido, as Ifet assumem papel de destaque na consumação das políticas de expansão, bem como no redimensionamento da formação do trabalhador (Pires, 2006).

Outro programa com impacto na organização das universidades federais é o Programa de Apoio a Planos de Reestruturação e Expansão das Universidades Federais (Reuni), que tem como meta a criação de condições para a ampliação do acesso e permanência dos estudantes nas universidades federais, no nível de graduação. $\mathrm{O}$ Reuni objetiva elevar a taxa de conclusão média dos cursos de graduação presenciais para $90 \%$ e aumentar para $18 / 1$ a razão alunos/professor, nos cursos de graduação presenciais, a contar do início de cada plano (Brasil, 2007b). Deve-se enfatizar que essas e outras iniciativas revelam que a relação governo federal e universidades federais, no Governo Lula, representa uma ruptura com a lógica e o tratamento que se testemunhou durante o Governo FHC.

Os dados demonstram que a transição do sistema de elite para o sistema de massa no Brasil tem se processado por meio do crescimento do setor privado, que passa a constituir-se como setor hegemônico no tocante ao volume de matrículas. A dimensão do setor privado dentro do sistema de massa atualmente em desenvolvimento no Brasil pode ser claramente visualizada pelo volume de matrículas brutas de 3.806.091, que, quando cotejado com a população de 18 a 24 anos de 2008 (23.242.000), corresponde a $16,4 \%$. Claro que esse é um dado isolado, mas ele nos permite visualizar a dimensão do setor privado no Brasil, assim como nos permite fazer uma conclusão ad hoc: o setor privado constitui-se praticamente em "sistema" de massa. Entretanto, a transição observada para o sistema de massa tem contribuição importante do setor público, cujo volume de matrícula é de 1.273.965, correspondente a 5,5\% da população de 18 a 24 anos. A sua TCM no período de 1995 a 2008, apesar de modesta, quando comparada ao setor privado, tem enorme impacto não apenas no tamanho do sistema, mas, sobretudo, na forma como o setor público opera. É um setor formado predominante por universidades públicas, cujo modus operandi é muito diferente do tipo médio de escola superior que caracteriza o setor privado. É importante destacar que foram as políticas de governo, dos dois governos, com clara linha de continuidade, que induziram o sistema a ingressar na fase da educação superior de massa.

\section{Considerações finais}

No curso histórico da sociedade brasileira já se encontra claramente delineada a fase do sistema de elite, o qual, por razões econômicas, políticas, sociais e culturais, vem sendo profundamente transformado por meio das políticas de corte 
"neoliberal-conservador" (Governo FHC) e "neoliberal-populista" (Governo Lula) (Gomes, 2008), fazendo emergir, apenas contemporaneamente, o sistema de massa. Contudo, estamos muito distantes de alcançar a meta de $30 \%$ de matrícula do grupo etário de 18 a 24 anos estabelecido pelo PNE. Baseado nos dados analisados, os quais devem ser apoiados por outros estudos, talvez possamos afirmar que a história da educação superior brasileira, no longo período que vai de 1810 a 1995, apresenta de forma bastante contundente as características descritas para o sistema de elite, um sistema fechado, meritocrático e altamente seletivo, particularmente destinado a incorporar os membros das classes sociais privilegiadas. Por longo período, o crescimento do sistema não constituiu preocupação efetiva das autoridades responsáveis pela formulação e implementação das políticas de educação superior. As taxas de crescimento foram, digamos, vegetativas e tão inexpressivas por tão longo período que a expansão do sistema basicamente foi condicionada pelo discurso dominante de que a universidade era privilégio e, como tal, sua relação com a esfera econômica era plenamente ajustada a promover os interesses das elites dominantes. Obviamente que mudanças importantes ocorreram durante esse período da história brasileira, inclusive com o aumento do número de matrículas e de IES públicas, mas não houve propriamente uma ruptura que permitisse aos membros das classes trabalhadoras, tradicionalmente alijadas de determinado tipo de capital cultural e escolar, a realização do desejo de cursar a educação superior.

Em relação ao sistema de massa que se encontra em desenvolvimento, há importantes questões que precisam ser debatidas e aprofundadas em estudos futuros. Uma questão que deve ser trabalhada é que, muito embora o termo "massificação" tenha se tornado de uso corrente na literatura da área, ele tem sido usado frequentemente como sinônimo de privatização. Consideramos que privatização e massificação não se referem ao mesmo processo político-social. O caso brasileiro nos ajuda a entender tais processos, porque a emergência do sistema de massa ocorre em grande parte por meio da privatização da oferta de vagas na ES. Entretanto, o sistema de massa ou o processo que o constitui, a massificação, pode ser analisado tomando como referência a democratização do acesso. Pode-se perguntar, neste sentido, como a transição para o sistema de massa se relaciona com a democratização da matrícula, de forma que rompesse com a lógica que expropriou as classes sociais trabalhadoras e de baixa renda do círculo virtuoso da educação.

Uma segunda questão que merece aprofundamento se refere à relação entre sistema de massa e qualidade do ensino. Neste caso, o sistema de massa tem sido tratado como um sistema de ensino massificado, portanto de baixa qualidade. Essa parece ser uma tendência real no caso brasileiro, particularmente no setor privado. Considere-se, por exemplo, que parte considerável da população estudantil se constitui de estudantes trabalhadores (ou trabalhadores estudantes?), os quais não 
possuem tempo físico útil para dedicar-se aos estudos e muitos dos quais também não adquiriram um habitus de estudo ao longo de sua trajetória escolar.

\section{Notas}

1. Para uma visão sistematizada do trabalho de Trow, ver Brennan (2004).

2. Proposição teórica preliminar sobre a distinção entre políticas de Estado e políticas de governo na educação superior é desenvolvida por Gomes e Azevedo (2009).

3. Não conseguimos dados que confirmassem a realização da previsão.

\section{Referências}

AMARAL, N.C. Financiamento da educação superior: Estado x mercado. São Paulo: Cortez; Piracicaba: Unimep, 2003.

BOURDIEU, P. Escritos de educação. Petrópolis: Vozes, 2001.

BRASIL. Decreto n. 6.095, de 24 de abril de 2007. Estabelece diretrizes para o processo de integração de instituições federais de educação tecnológica, para fins de constituição dos Institutos Federais de Educação, Ciência e Tecnologia, no âmbito da Rede Federal de Educação Tecnológica. Diário Oficial da União, Brasília, DF, 25 abr. 2007a.

BRASIL. Decreto n. 6.096, de 24, de abril de 2007. Institui o Programa de Apoio a Planos de Reestruturação e Expansão das Universidades Federais - Reuni. Diário Oficial da União, Brasília, DF, 25 abr. 2007b.

BRASIL. Lei n. 9.678, de 3 de julho de 1998. Institui a Gratificação de Estímulo à Docência no Magistério Superior, e dá outras providências. Alterada pela Lei n. 11.087, de 4 de janeiro de 2005. Diário Oficial da União, Brasília, DF, 5 jan. 2005.

BRASIL. Lei n. 10.172, de 9 de janeiro de 2001. Aprova o Plano Nacional de Educação e dá outras providências. Diário Oficial da União, Brasília, DF, 10 jan. 2001.

BRASIL. Medida Provisória n. 1.827, de 27 de maio de 1999. Dispõe sobre o Fundo de Financiamento ao Estudante do Ensino Superior e dá outras providências. Diário Oficial da União, Brasília, DF, 28 maio 1999.

BRASIL. Ministério da Educação. Instituto Nacional de Estudos e Pesquisas Educacionais (Inep). Resultados e tendências da educação superior no Brasil. Brasília, DF, 2000a.

BRASIL. Ministério da Educação. Instituto Nacional de Estudos e Pesquisas Educacionais (Inep). Desempenho do sistema educacional brasileiro: 1994-1999. Brasília, DF, 2000b. Disponível em: <www.inep.gov.br>. Acesso em: 5 set. 2009. 
BRASIL. Ministério da Educação. Instituto Nacional de Estudos e Pesquisas Educacionais (Inep). Educação brasileira: políticas e resultados. Brasília, DF, 2000c. Disponível em: <www.inep.gov.br>. Acesso em: 5 set. 2009.

BRASIL. Ministério da Educação. Instituto Nacional de Estudos e Pesquisas Educacionais (Inep). Expansão das universidades federais: o sonho se torna realidade!; período de 2003 a 2006. Brasília, DF, 2006. Disponível em: <www.inep.gov.br>. Acesso em: 5 set. 2009.

BRENNAN, J. The social role of the contemporary university: contradictions, boundaries and change. In: TEN YEARS ON: changing education in a changing world. Milton Keynes: The Open University, 2004. p. 22-26.

CHAUÍ, M. Universidade em ruínas. In: TRINDADE, H. (Org.). A universidade em ruínas na república dos professores. 2. ed. Petrópolis: Vozes, 2000. p. 211-222.

CORBUCCI, P.R. Financiamento e democratização do acesso à educação superior no Brasil: da deserção do Estado ao projeto de reforma. Educação \& Sociedade, Campinas, v. 25, n. 88, p. 677-701, out. 2004.

CUNHA, L.A. O público e o privado na educação superior brasileira: fronteira em movimento. In: TRINDADE, H. (Org.). A universidade em ruínas na república dos professores. 2. ed. Petrópolis: Vozes, 2000. p. 39-56.

CUNHA, L.A. O ensino superior no octênio FHC. Educação \& Sociedade, Campinas, v. 24, n. 82, p. 37-61, abr. 2003.

CUNHA, L.A. Desenvolvimento desigual e combinado no ensino superior: Estado e mercado. Educação \& Sociedade, Campinas, v. 25, n. 88, p. 795-817, out. 2004

DIAS SOBRINHO, J. Quase mercado, quase educação, quase qualidade: tendências e tensões na educação superior. In: DIAS SOBRINHO, J. Universidade e a avaliação: entre a ética e o mercado. Florianópolis: Insular, 2002.

DOURADO, L.F. Reforma do Estado e as políticas para a educação superior no Brasil nos anos 90. Educação \& Sociedade, Campinas, v. 23, n. 80, p. 235-253, 2002.

DOURADO, L.F. (Org.). Políticas e gestão da educação no Brasil: novos marcos regulatórios. São Paulo: Xamã, 2009.

GOMES, A.M. Política de avaliação da educação superior: controle e massificação. Educação \& Sociedade, Campinas, v. 23, n. 80, p. 275-298, 2002.

GOMES, A.M. Estado, mercado e educação superior no Brasil: um modelo analítico. Educação \& Sociedade, Campinas, v. 24, n. 84, p. 839-872, set. 2003. 
GOMES, A.M. As reformas e políticas da educação superior no Brasil: avanços e recuos. In: MACEBO, D.; SILVA JR., J.R.; OLIVEIRA, J.F. Reformas e políticas: educação superior e pós-graduação no Brasil. Campinas: Átomo \& Alínea, 2008. v. 1, p. 23-51.

GOMES, A.M.; AZEVEDO, J.M.L. Notas teóricas sobre regulação e educação superior. In: DOURADO, L.F. (Org.). Políticas e gestão da educação no Brasil: novos marcos regulatórios. São Paulo: Xamã, 2009. p. 183-191.

OLIVEIRA, A.P. A relação entre o público e o privado na educação superior no Brasil e o Programa Universidade Para Todos (Prouni). 2007. Tese (Doutorado) - Programa de Pós-Graduação em Educação, Universidade Federal de Pernambuco, Recife.

OLIVEIRA, J.F. A reestruturação da educação superior no Brasil e o processo de metamorfose das universidades federais: o caso da Universidade Federal de Goiás (UFG). 2000. Tese (Doutorado) - Universidade de São Paulo, São Paulo.

OLIVEIRA, J.F; CATANI, A.M. Educação superior no Brasil: reestruturação e metamorfose das universidades públicas. Petrópolis: Vozes, 2002.

OLIVEIRA, J.F; CATANI, A.M; DOURADO, L.F. Política educacional, mudanças no mundo do trabalho e reforma curricular dos cursos de graduação no Brasil. Educação E Sociedade, Campinas, v. 22, n. 75, p. 67-83, 2001.

PAULA, M.F. Reforma da educação superior do Governo Lula: as políticas de democratização do acesso em foco. Revista Argentina de Educación Superior, Buenos Aires, v. 1, n. 1, p. 152-172, nov. 2009. Disponível em: <www.untref.edu.ar/raes>. Acesso: em 15 jan. 2009.

PINTO, J.M.R. O acesso à educação superior no Brasil. Educação \& Sociedade, Campinas, v. 25, n. 88, p. 727-756, out. 2004.

PIRES, L.L.A. A criação de universidades tecnológicas no Brasil: uma nova institucionalidade para a educação superior? 2006. Tese (Doutorado) - Universidade Federal de Goiás, Goiânia.

SAVIANI, D. Histórias das ideias pedagógicas no Brasil. Campinas: Autores Associados, 2007.

SCOTT, P. The meanings of mass higher education. Milton Keynes: The Open University, 1995.

SGUISSARDI, V. (Org.). Educação superior: velhos e novos desafios. São Paulo: Xamã, 2000. 
SGUISSARDI, V. Modelo de expansão da educação superior no Brasil: predomínio privado/mercantil e desafios para a regulação e a formação universitária. Educação $\mathcal{E}$ Sociedade, Campinas, v. 29, n. 105, p. 991-1022, set./dez. 2008.

SGUISSARDI, V.; SILVA JUNIOR., J.R. Novas faces da educação superior no Brasil: reforma do Estado e mudança na produção. 2. ed. São Paulo: Cortez; Bragança Paulista: USF, 2001.

TROW, M. Problems in the transition from elite to mass higher education. Berkeley: Carnegie Comission on Higher Education, 1973.

TROW, M. Reflections on the transition from elite to mass to universal access: forms and phases of higher education in modern societies since WWII. Berkeley: University of California, 2005. Disponível em: <http://repositories.cdlib.org/igs/WP2005-4>.

WEFFORT, F. Por que democracia? São Paulo: Brasiliense, 1984.

Recebido em 13 de maio de 2010.

Aprovado em 3 de novembro de 2011. 